Добрушина М. Г., Кавун В. В., Галабурда Д. А., Маслей В. Н., Москалев С. И., Боклагова И. Н., Кушниренко С. И.

Государственное предприятие «Конструкторское бюро «Южное» им. М. К. Янгеля». Украина, г. Днепр

\title{
АСПЕКТЫ РАЗРАБОТКИ \\ РАЗМЕРОСТАБИЛЬНОЙ КОНСТРУКЦИИ СКАНЕРА ВЫСОКОГО РАЗРЕШЕНИЯ
}

\begin{abstract}
Представлены результаты разработки размеростабильной конструкции корпуса сканера высокого разрешения космического аппарата дистанционного зондирования Земли; рассмотрены варианты конструктивного исполнения корпуса сканера в виде монолитной оболочечной конструкции и ферменного типа; выбран вариант исполнения конструкции из трехслойных панелей с углепластиковыми обшивками, подкрепленных по периметру рамой из углепластиковых труб, соединенных титановыми фитингами; представлен опыт разработки размеростабильных конструкций оптииеских приборов космического применения. [dx.doi.org/10.29010/080.11]
\end{abstract}

Ключевые слова: размеростабильные конструкиии оптических приборов; трехслойная сотовая конструкиия; композищионные материалы; углепластик.

\section{Введение}

Одной из основных полезных нагрузок космических аппаратов дистанционного зондирования Земли являются оптические приборы высокого разрешения. К несущим конструкциям оптических приборов предъявляются высокие требования к сохранности взаимного положения площадок для крепления оптических элементов (зеркал, фотоприемников) - изменения линейных размеров не должны превышать от единиц до десятков микрон, повороты площадок под приборы не должны превышать от нескольких секунд до единиц угловых минут. Большую долю в изменение размеров конструкции вносят деформации под воздействием перепадов температур. Изготовление конструкций из композиционных материалов на основе углеродных волокон, имеющих низкие значения коэффициента температурного расширения (КТР) на уровне $\pm 1 \times 10^{-6} 1 /{ }^{\circ} \mathrm{C}$, позволяют свести к минимуму температурные деформации. Разработку и изготовление экспериментальных терморазмеростабильных конструкций космических аппаратов из углепластика ГП «КБ «Южное» проводит, начиная с 1988 г. Полученный опыт позволил приступить к разработке конструкций корпусов оптических приборов высокого разрешения космического применения. В ГП «КБ «Южное» разработан и изготовлен ряд конструкций оптических приборов с осевой и внеосевой оптическими схемами.
В настоящее время проводятся работы по созданию конструкции сканера разрешением около 2,5 м с внеосевой оптической схемой.

\section{Постановка задачи}

Разработка корпуса сканера выполняется исходя из условий обеспечения следующих основных требований:

- допускаемые смещения площадок под установку оптических элементов на уровне 10 мкм;

- допускаемые наклоны площадок под установку оптических элементов на уровне 5 угл.с;

- требование по жесткости - собственная частота до 40 Гц вдоль продольной оси.

В процессе разработки сканера требования менялись - изменилась оптическая схема, требование к допускаемому наклону площадок ужесточилось с первоначального значения 30 угл.с до заданного в настоящее время 5 угл.с. Требование по частотам изменилось с 25 Гц до 40 Гц.

Разработка конструкции ведется в пределах пространства, ограниченного наружными габаритами, расположением оптических элементов и ходом лучей, заданными оптической схемой.

Эти требования и ограничения в основном определяют конструкцию корпуса сканера. Требование по размеростабильности определяет выбор материала, требования по жесткости и оптическая схема - геометрическую конфигурацию конструкции. 


\section{Выбор варианта конструктивно- технологического исполнения корпуса}

Выбор конструктивно-технологического исполнения связан с типом оптической схемы, требованиями к сохранности положения оптических элементов, необходимостью обеспечения массовой эффективности конструкции и поиском приемлемых технологических решений.

В процессе разработки корпуса сканера были рассмотрены три варианта конструктивно-технологического исполнения корпуса сканера:

- монолитный оболочечный корпус;

- ферменный корпус;

- панельный корпус.

В 2010 г., исходя из начальных требований, была разработана несущая конструкция сканера с корпусом монолитного оболочечного типа.

Несущая конструкция состоит из двух частей корпуса и плиты, механически соединенных между собой.

Корпус сканера представляет собой монолитную оболочечную конструкцию в виде прямоугольного параллелепипеда с толщиной стенок около 20 мм. Плита монолитная толщиной 30 мм. Материал корпуса и плиты - многослойный углепластик. Для крепления оптических элементов в углепластиковую конструкцию вклеены втулки из титанового сплава. Для крепления к космическому аппарату на корпусе неразъемно крепятся три кронштейна из титанового сплава.

Общий вид несущей конструкции сканера с корпусом оболочечного типа приведен на рисунке 1.

Характеристики несущей конструкции сканера с корпусом оболочечного типа:

- габаритные размеры $\sim 700 \times 600 \times 450$ мм;

- масса конструкции - 55 кг;

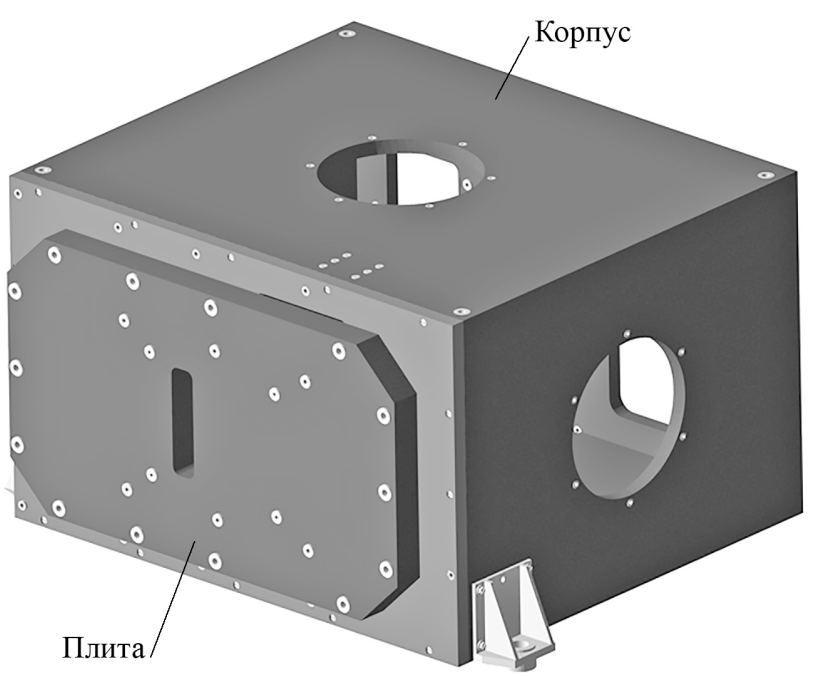

Рис. 1. Общий вид несущей конструкции сканера с корпусом оболочечного типа
- рабочий диапазон температур - $(20 \pm 2)^{\circ} \mathrm{C}$;

- линейные перемещения площадок крепления оптических элементов - не более 0,01 мм;

- угловые перемещения площадок крепления оптических элементов - не более 30 угл.с.

Для изготовления заготовки корпуса был разработан метод трехмерной выкладки на оправке. Данный метод был успешно опробован на разработанной ранее конструкции сканера разрешением 1 м, изображенной на рисунке 2.

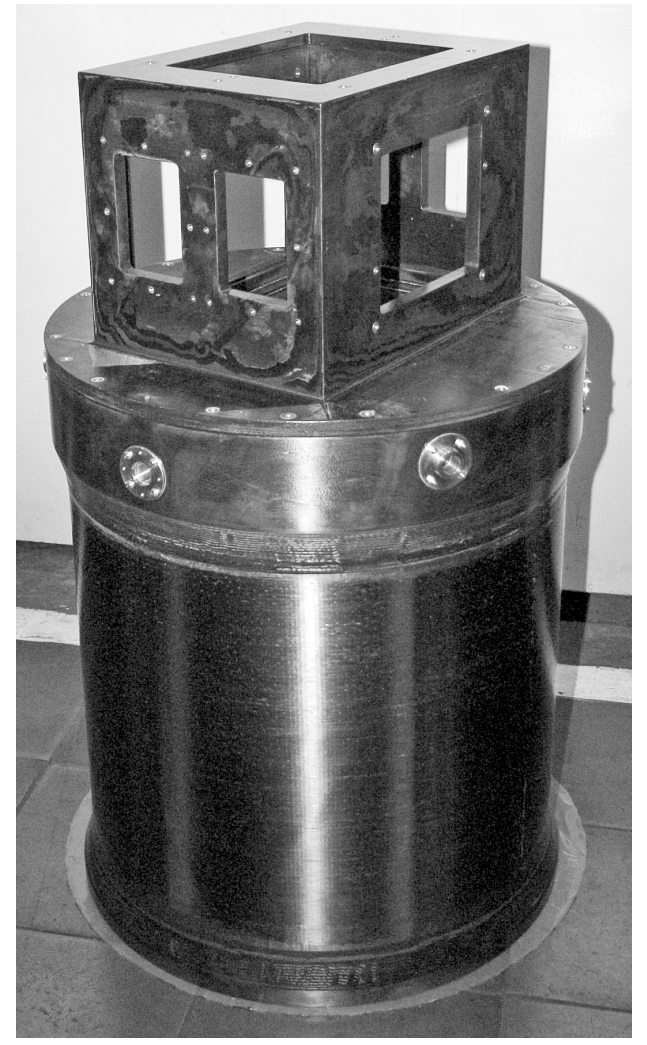

Рис. 2. Общий вид конструкции сканера разрешением 1 м

Одним из основных элементов конструкции сканера разрешением 1 м является корпус, который выполнен в виде прямоугольного толстостенного параллелепипеда с размерами $\sim 0,5 \times 0,5 \times 0,6$ м с цилиндрической пластиной диаметром $\sim 0,9$ м на одной из его граней. Толщина стенки корпуса $\sim 20$ мм. Масса корпуса - 49 кг.

Расчетные значения отклонений положения площадок под установку оптических элементов конструкции сканера, приведенной на рисунке 2, в рабочем диапазоне температур $(20 \pm 2)^{\circ} \mathrm{C}$ составили:

- линейные перемещения - не более 0,01 мм;

- угловые перемещения не более 5 угл.с.

Далее, с целью снижения массы конструкции была разработана несущая конструкция сканера с корпусом, выполненным в виде фермы. Размер ферменного корпуса $\sim 700 \times 800 \times 600$ мм. К корпусу 
крепится монолитная углепластиковая плита размерами $\sim 700 \times 600 \times 30$ мм. Снаружи корпус закрыт защитными экранами трехслойной сотовой конструкции с углепластиковыми обшивками.

Материал труб ферменного корпуса - углепластик, материал фитингов - титановый сплав. Общий вид корпуса сканера ферменного типа приведен на рисунке 3 .

Основные характеристики несущей конструкции для сканера с корпусом ферменного типа:

- линейные перемещения площадок крепления оптических элементов - не более 0,01 мм;

- угловые перемещения площадок крепления оптических элементов - не более 5 угл.с;

- рабочий диапазон температур - $(20 \pm 2)^{\circ} \mathrm{C}$;

- масса - 26 кг.

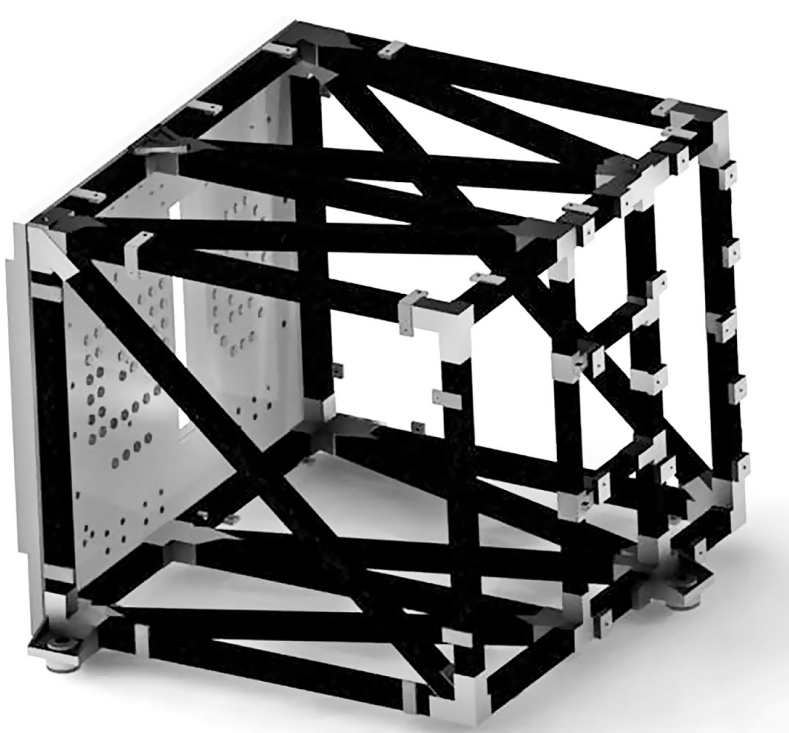

Рис. 3. Общий вид корпуса сканера ферменного типа

Препятствиями для применения конструкции ферменного типа стала необходимость введения светозащитной оболочки из трехслойных панелей, которая увеличивает габариты конструкции и трудность изготовления фитингов с косыми лучами, обеспечивающих требования по размеростабильности.

В настоящее время разработан корпус сканера панельного типа и начато изготовление его технологического образца.

Основной элемент несущей конструкции сканера - корпус в виде объемной конструкции, состоящей из трехслойных панелей, соединенных между собой механически и дополнительно склеенных уголками. К корпусу крепятся трубчатые и панельные оправы зеркал и другие элементы конструкции для крепления блоков электроники. Габаритные размеры несущей конструкции сканера $1000 \times 800 \times 640$ мм. Масса - 38,5 кг.
Общий вид панельного корпуса сканера приведен на рисунке 4.

Все панели корпуса имеют обшивки из углепластика и сотовый заполнитель из алюминиевой фольги. Для увеличения жесткости конструкции панели окантованы по периметру каркасом из углепластиковых труб, соединенных между собой

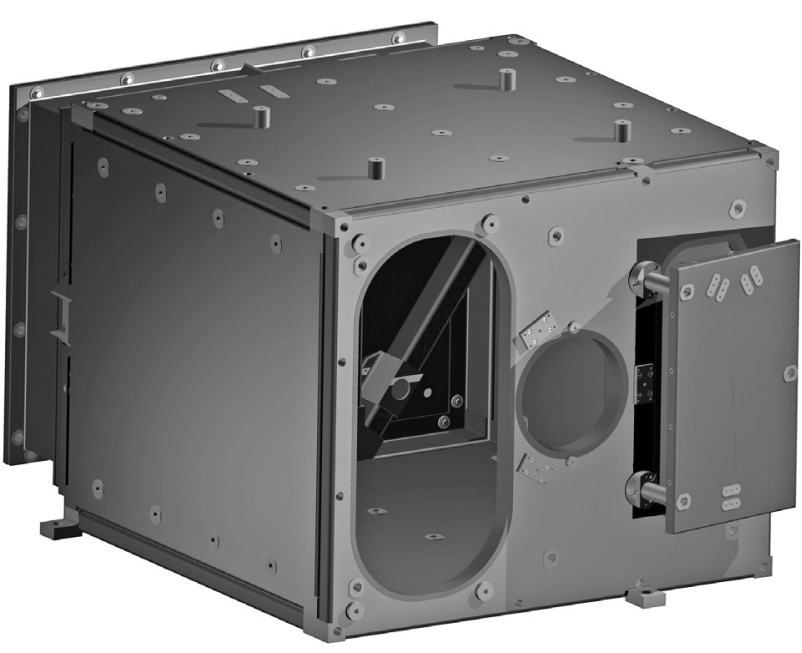

Рис. 4. Общий вид панельного корпуса сканера

фитингами из титанового сплава. Во все панели вклеены втулки из титанового сплава для крепления зеркал, диафрагм и др. В конструкции разработанного панельного корпуса сканера применены конструктивно-технологические решения, ранее использованные в конструкциях сканеров разработки ГП «КБ «Южное».

В последние годы разработаны и изготовлены две несущие конструкции крупногабаритных сканеров с размерами около $2300 \times 1500 \times 1300$ мм. Силовая часть каждой несущей конструкции состоит из четырех панелей, двух световых перегородок, узла крепления фотоприемников в виде оболочки толщиной 5 мм в форме трехгранной призмы. Частью силовой конструкции являются три съемные оправы под установку зеркал. Две из оправ выполнены в виде плоских рам с трубчатыми стержнями из углепластика и титановыми фитингами. Панели и световые перегородки изготовлены в виде трехслойных панелей с углепластиковыми обшивками и алюминиевым сотовым заполнителем. По периметру панелей вклеена рама, состоящая из углепластиковых труб, соединенных фитингами из титанового сплава. Общий вид несущей конструкции сканера приведен на рисунке 5.

Несущие конструкции сканеров прошли динамические испытания. Достигнутые жесткости характеризуются собственными частотами конструкций:

- по продольной оси - более 70 Гц; 
- в поперечных направлениях - более 35 Гц;

- первая собственная частота кручения вокруг продольной оси - более 75 Гц.

В разработанном корпусе сканера две оправы зеркал также выполнены из прямоугольных углепластиковых труб, соединенных с помощью клея титановыми фитингами.

Одной из основных деталей корпуса сканера является корпус для крепления фотоприемников в виде толстостенного короба, изготавливаемого методом трехмерной выкладки на оправке.

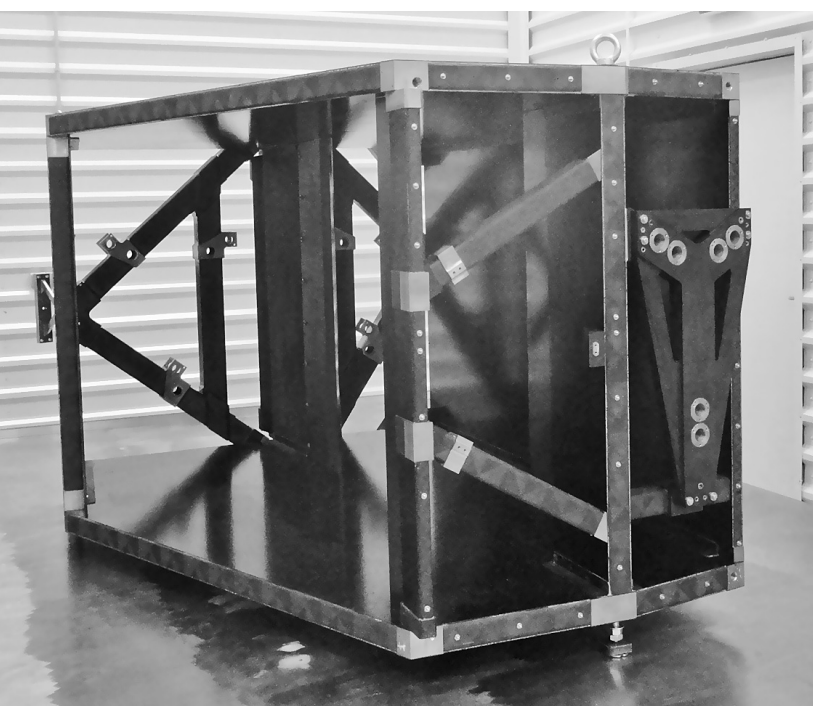

Рис. 5. Общий вид несущей конструкции сканера

В рамках исследовательских испытаний проведена отработка технологии вклейки в трехслойные панели втулок различных типов. В корпусе сканера в наиболее нагруженных местах применяются втулки, состоящие из двух частей, которые устанавливаются с двух противоположных сторон панели, свинчиваются между собой и приклеиваются к заполнителю и обшивкам. Эскиз втулки приведен на рисунке 6. Результаты испытаний подтвердили правильность выбора типа втулок.

Проведенные прочностные расчеты и расчеты температурных деформаций корпуса сканера показали, что спроектированная таким образом конструкция удовлетворяет требованиям прочности, жесткости и температурных деформаций. Максимальные суммарные перемещения конструкции составляют 0,11 мм для случая полета КА в составе $\mathrm{PH}$, и 0,12 мм для случая транспортирования КА. Жесткостные параметры оптической системы конструкции также очень высокие. Так линейные перемещения площадок крепления оптических элементов при настройке на Земле находятся на уровне 2-4 микрон, а угловые на уровне 6-7 угловых секунд при требовании 18 угл.с и около 1 угл.с при требовании 5 угл.с. Диаграмма суммарных переме-

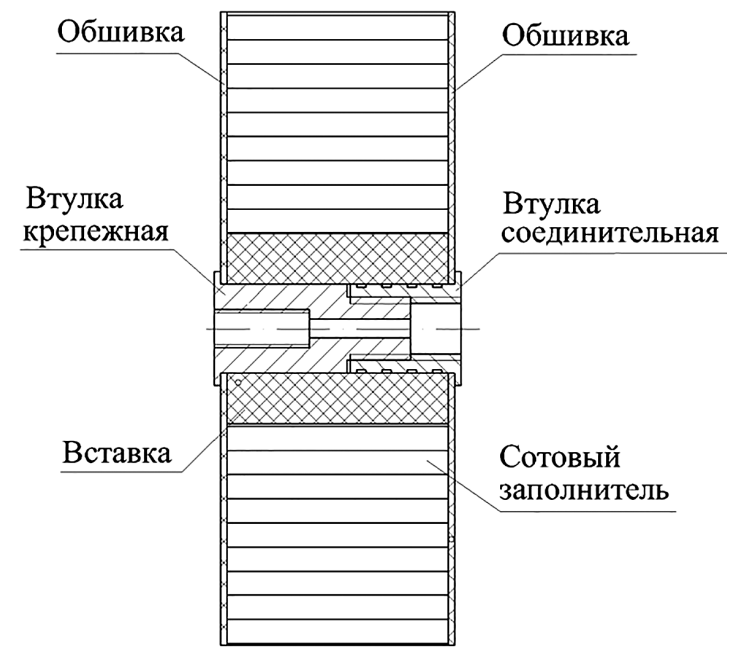

Рис. 6. Эскиз типовой втулки, применяемой в панелях корпуса сканера

щений корпуса сканера для случая полета в составе РН приведена на рисунке 7.

Используя в конструкции сканера трехслойные сотовые панели с углепластиковыми обшивками, удалось добиться линейных перемещений площадок крепления оптических элементов друг относительно друга, на уровне 4 микрон, и угловых поворотов на уровне 1-2 угловых секунд. Диаграмма суммарных перемещений корпуса сканера при температурном нагружении приведена на рисунке 8.

В связи с высоким требованием по взаимному положению площадок под оптические элементы предусмотрено проведение автономной отработки корпуса сканера по подтверждению его геометрической стабильности.

Измерения угловых и линейных перемещений площадок корпуса проводятся при равномерном его нагреве на $4^{\circ} \mathrm{C}$ и при температурном перепаде между гранями корпуса на $4^{\circ} \mathrm{C}$.

Испытываемая конструкция устанавливается на массивную технологическую плиту на три точки с обеспечением температурной развязки относительно плиты.

Для исключения влияния окружающей среды испытываемый корпус изолируется теплозащитным кожухом из пенопласта, который монтируется вокруг корпуса.

Равномерный нагрев или температурные перепады по корпусу создаются пленочными нагревателями, устанавливаемыми на корпусе и управляемыми термореле.

На площадки, наклоны которых под воздействием температур измеряются, крепятся имитаторы из толстостенного стекла с обеспечением их температурной развязки относительно точек их крепления к конструкции. По центру каждого имитатора крепится зеркальце. 


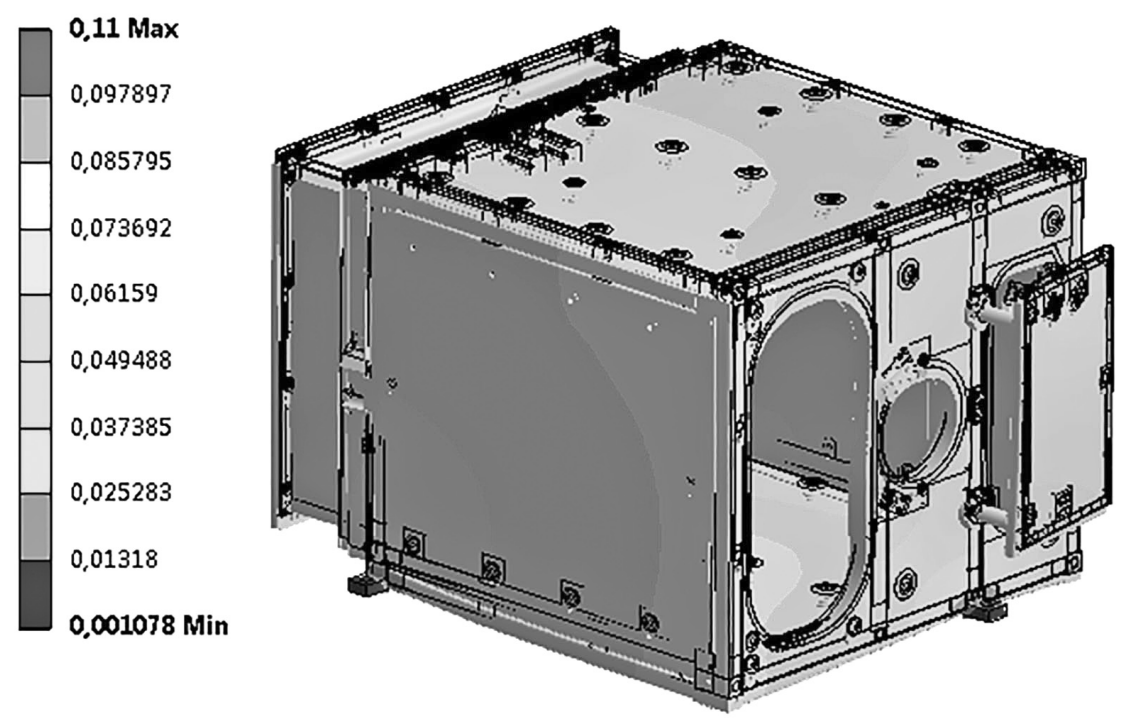

Рис. 7. Диаграмма суммарных перемещений корпуса сканера, мм
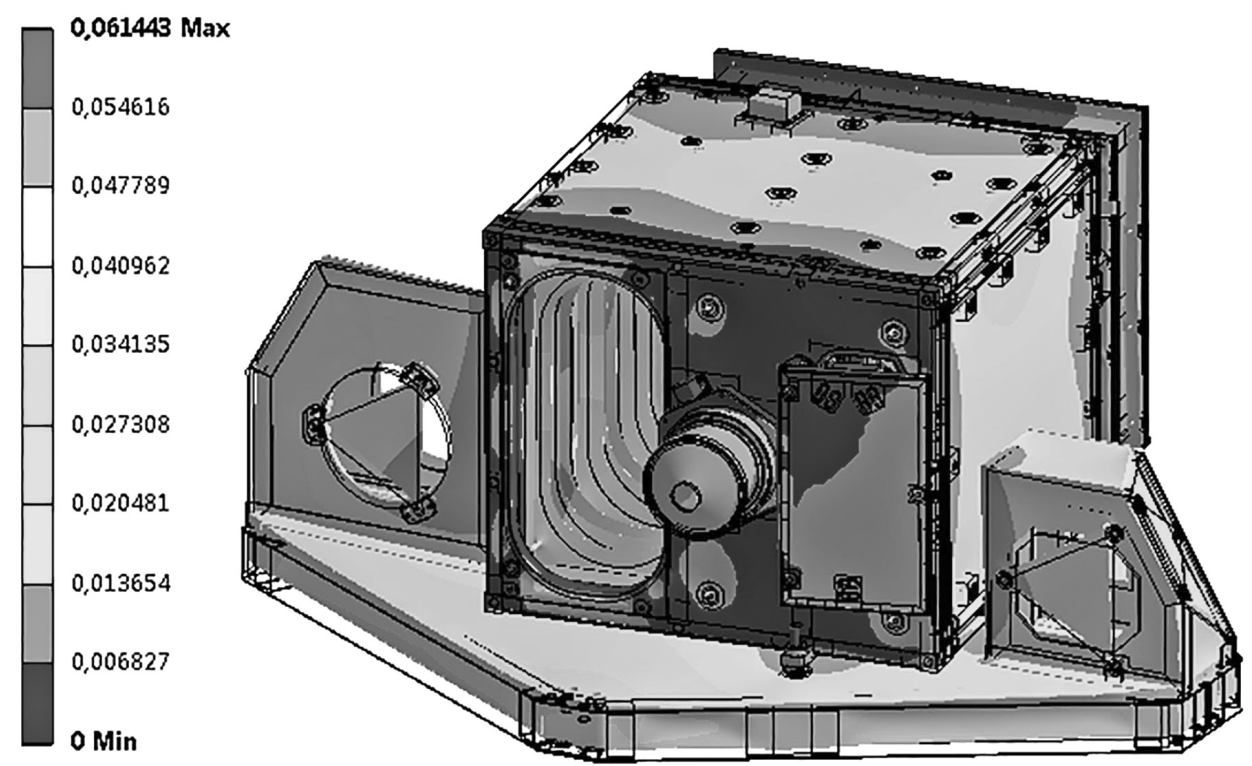

Рис. 8. Диаграмма суммарных перемещений корпуса сканера при температурном нагружении, мм

Для измерения наклонов площадок используются лазерные оптические устройства (ЛОУ), состоящие из лазера, посылающего луч на зеркальце, установленное на имитаторе, и приемного устройства, фиксирующего положение отраженного от зеркальца луча.

Приемное устройство ЛОУ - камера с ПЗСприемником, которая устанавливается на плите возле корпуса сканера вместе с лазером на одной стойке с помощью магнитных прижимов.

Во время испытаний выполняется нагрев корпуса с обеспечением заданного по расчету поля температур на корпусе и определение смещения отраженного от зеркальца луча лазера на камере ЛОУ.
Подобная методика измерений была успешно опробована на конструкции сканера, изображенного на рисунке 5. Испытания показали сохранность положения площадок под оптические элементы на уровне 5 мкм в линейных направлениях и менее 2 угл.с в угловых направлениях.

\section{Выводы}

В соответствии с предъявленными требованиями разработан корпус сканера высокого разрешения для космического аппарата дистанционного зондирования Земли. Выбраны конструктивно-технологические решения для исполнения конструктивных 
элементов. Решения базируются на опыте, приобретенном при изготовлении размеростабильных конструкций корпусов сканеров и на результатах исследовательских испытаний. Температурные деформации корпуса и жесткостные характеристики конструкции, полученные расчетным путем, не превышают единиц микрон и единиц угловых секунд, что подтверждает правильность принятых конструктивно-технологических решений. Начато изготовление технологического образца корпуса сканера. Предусмотрено подтверждение его размеростабильности экспериментальным путем.

\section{Литература}

[1] Добрушина М. Г. Обзор терморазмеростабильных конструкций космических аппаратов / Добрушина М. Г., Кавун В. В., Москалев С. И., Щудро А. П.// Космическая техника и ракетное вооружение. 2015. - № 2. - C. 38-42.

[2] Кореннов Ю. А. Расчет интегральных характеристик многослойных композиционных материалов /
Кореннов Ю. А. Шовкопляс Ю. А., Щудро А. П. // Украинская конференция по космическим исследованиям: материалы 16 Украинской конференции по космическим исследованиям (22-27 августа 2016 года). - Киев, 2016. - С. 109.

[3] Кушниренко С. И. Особенности расчета температурных деформаций оптической полезной нагрузки из композиционных материалов / Кушниренко С. И., Кореннов Ю. А., Щудро А. П. //6-я международная конференция «Космические технологии: настоящее и будущее» (23-26 мая 2017 года). Днепр, 2017. - С. 45.

[4] Кавун В. В. Обеспечение терморазмеростабильности конструкций из композиционных материалов с использованием лазерно-оптических устройств / Кавун В. В., Кудреватых А. Т. Кулик А. С., Москалев С. И., Сохач Ю. В., Щудро А. П. //6-я международная конференция «Космические технологии: настоящее и будущее» (23-26 мая 2017 года). Днепр, 2017. - С. 75.

Dobrushyna M. H., Kavun V. V., Halaburda D. A., Maslyey V. N., Moskalov S. I., Boklahova I. N., Kushnirenko $S$. I.

Yuzhnoye, State-owned Design Office named after M. K. Yangel. Ukraine, Dnipro

\section{ASPECTS OF DEVELOPMENT OF THE DIMENSIONALLY STABLE STRUCTURE OF HIGH RESOLUTION IMAGER}

This article shows results of development of the dimensionally stable structure of body frame for high resolution imager designed for Earth remote sensing satellite; analysis of structural variations of the imager body frame designed in the same of integral shell-and-frame construction; selection of design for sandwichtype honeycomb panels with carbon fiber sheets peripherally stiffened with frame, which consist from carbon fiber tubes connected with titanium fittings; experience in development of dimensionally stable structure for spaceworthy optics. [dx.doi.org/10.29010/080.11]

Keywords: dimensionally stable structure; optics; sandwich honeycomb panel; composites; carbon fiber.

\section{References}

[1] Dobrushyna M. Overview of thermally and dimensionally stable structures for spacecrafts/ Dobrushyna M., Kavun V., Moskalov S., Schudro A. // Space technology and rocketry magazine - 2015. - Number 2. - P. 38-42.

[2] Korennov Y. Solution of integral characteristics of multilayered composite materials / Korennov Y., Shovkoplyas Y., Schudro A. // $16^{\text {th }}$ Ukrainian conference on space research (22-27 august) - Kiev, 2016. - P. 109.

[3] Kushnirenko S. Features of calculating temperature deformations of optical payloads made of composite materials/ Kushnirenko S., Korennov Y., Schudro A. $/ / 6^{\text {th }}$ International conference «Space technologies: present and future» (23-26 may) - Dnipro, 2017. - P. 45.

[4] Kavun V. Assurance of thermal-dimensional stability of structures made of composite materials by means of laser e equipment/Kavun V., Kudrevatyh A., Kulyk A., Moskalov S., Sohach Y., Schudro A.// $6^{\text {th }}$ international conference «Space technologies: present and future» (23-26 may) - Dnipro, 2017. -P. 75. 